\title{
The Giant Grape-Like Enterogenous Cyst Extending from the Upper Cervical Canal to the Ambient Cistern: Case Report and Literature Review
}

\author{
Han Chen ${ }^{1}$, Paul E. Kaloostian ${ }^{2 *}$, Franklin Westhout ${ }^{1}$, Shah-Naz Khan ${ }^{1}$ \\ ${ }^{1}$ Department of Neurosurgery, University of New Mexico Albuquerque, USA \\ ${ }^{2}$ Department of Neurosurgery, The Johns Hopkins University, Baltimore, USA \\ Email: "pkaloos1@jhmi.edu
}

Received March 19, 2013; revised April 19, 2013; accepted May 3, 2013

Copyright (c) 2013 Han Chen et al. This is an open access article distributed under the Creative Commons Attribution License, which permits unrestricted use, distribution, and reproduction in any medium, provided the original work is properly cited.

\begin{abstract}
Objective and Importance: The authors report the first known case of a giant multiloculated grape-like enterogenous cyst extending from the upper cervical canal to the ambient cistern. Clinical Presentation/Methods: We report the case of a 40-year-old male who had a prior transmastoid craniotomy at an outside facility 14 months prior with an indeterminate diagnosis, who presented to the University of New Mexico with recurrent headaches and nausea. Scans demonstrated a giant multiloculated cystic lesion in the right cerebellopontine angle that extended superiorly and inferiorly with brainstem compression and hydrocephalus. Intervention/Results: We took the patient to the operating room for a retrosigmoid suboccipital craniectomy for tumor resection. Post-operatively, the patient improved but required ventriculoperitoneal shunting for continued communicating hydrocephalus. Conclusion: This is the first known case of a giant multiloculated grape-like enterogenous cyst extending simultaneously from the upper cervical canal to the ambient cistern. Enterogenous cysts should be considered on the differential diagnosis of giant grape-like lesions extending from the cervical canal to the prepontine cistern.
\end{abstract}

Keywords: Enterogenous; Giant; Cervical; Pre-Pontine; Grape

\section{Objective and Importance}

The authors report the first known case of a giant multiloculated grape-like enterogenous cyst extending from the upper cervical canal to the ambient cistern.

\section{Clinical Presentation}

We report the case of a 40-year-old male who had a prior craniotomy at an outside facility 14 months prior with an indeterminate diagnosis, who presented to the University of New Mexico with new onset headaches and nausea. Scans demonstrated a giant multiloculated cystic lesion extending from the upper cervical canal, into the cerebellopontine angle, and finally up into the ambient cistern. This mass was causing brainstem compression and obstructive hydrocephalus (Figures 1-6).

\section{Intervention}

We took the patient to the operating room for a retro-

*Corresponding author. sigmoid suboccipital craniectomy for tumor resection. We identified at least 10 separate loculated compartments filled with xanthochromic looking fluid that we fenes trated and resected. The inferior portion attached to the upper cervical cord and medulla was not resected. Pathology demonstrated the presence of abundant mucin secretion and glandular epithelium. CAM 5.2 highlights the presence of abundant glandular epithelium. EMA was also positive highlighting the presence of fibrotic underlying leptomeninges. CDX-2 was positive in this glandular epithelium. PAS positivity highlights the presence of abundant mucin secretion and glandular epithelium (Figures 7 and 8). Post-operatively the patient improved neurologically but required ventriculoperitoneal shunting for continued communicating hydrocephalus and to allow for healing of his leaking wound (Figure 9).

\section{Discussion}

Enterogenous cysts, also known as endodermic or neuroepithelial cyst, are benign congenital lesions that were first described by Puusepp in 1934 [1]. They arise from 


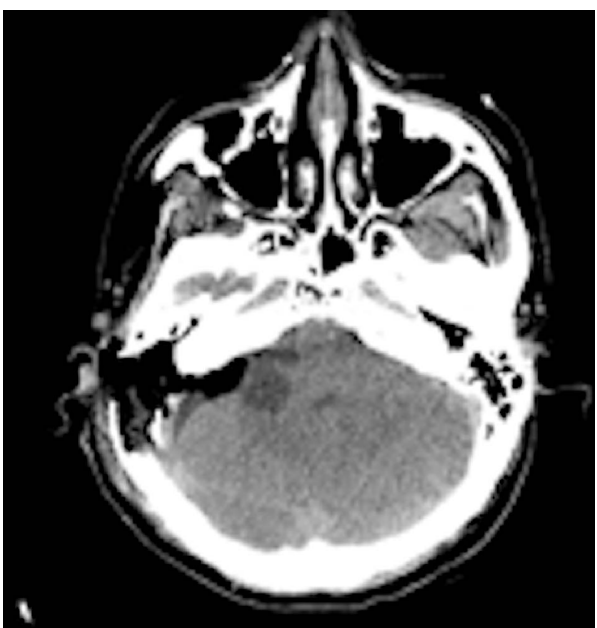

Figure 1. Post-operative CT scan after initial transmastoid surgery at outside hospital showing minimal residual cyst remaining. Diagnosis was not made from pathological reports at that time.

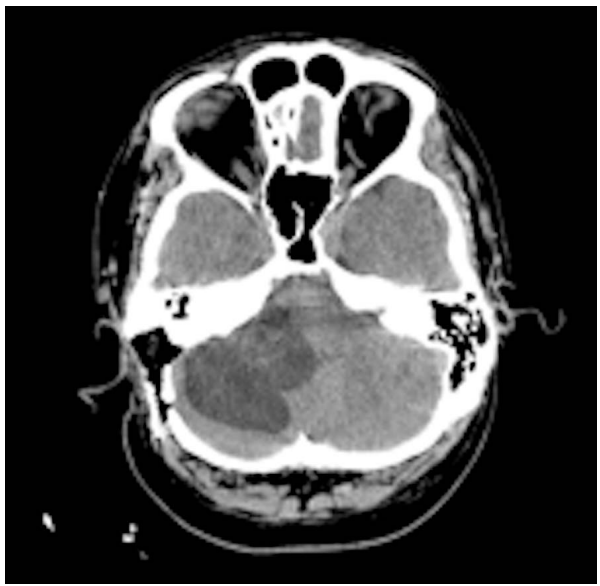

Figure 2. Patient presents to our facility 14 months later with recurrent symptoms and giant mass with brainstem compression and obstructive hydrocephalus.

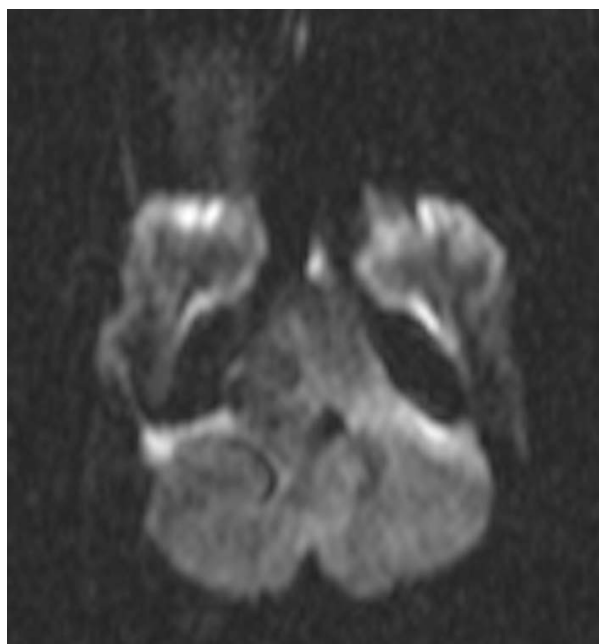

Figure 3. Diffusion MRI showing no restricted diffusion.

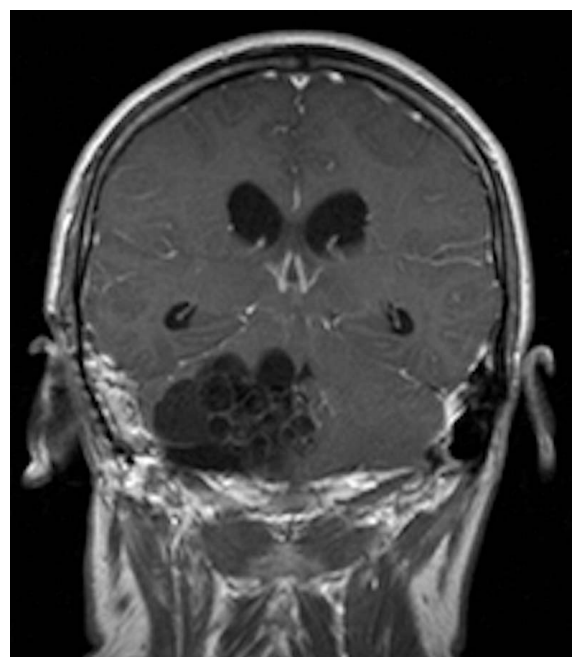

Figure 4. Coronal MRI post contrast showing this giant grape-like mass with multiple different compartments.

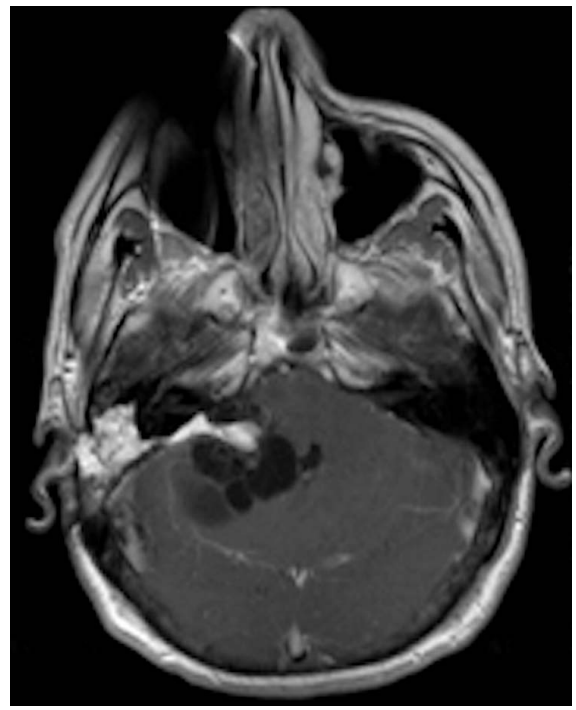

Figure 5. Axial MRI post contrast showing this giant grapelike mass.

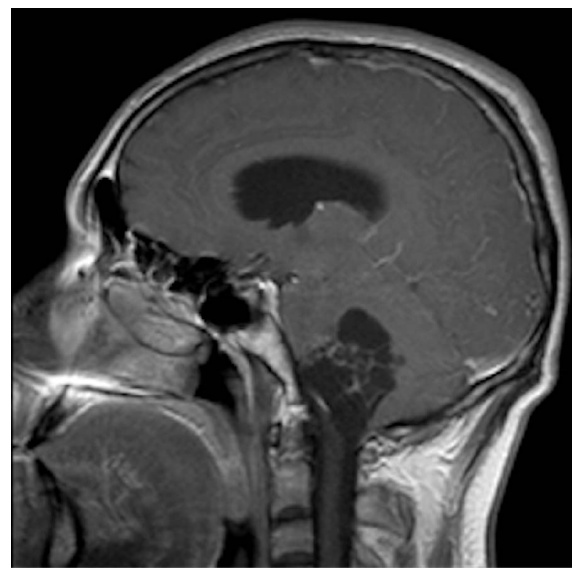

Figure 6. Sagittal MRI post contrast showing this giant grape-like mass. 


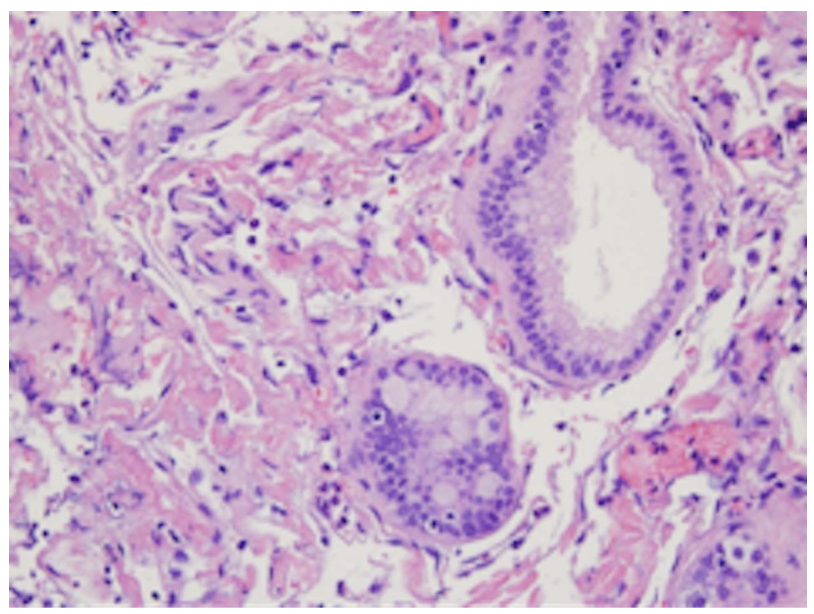

Figure 7. Histological analysis demonstrated presence of abundant mucin secretion and glandular epithelium.

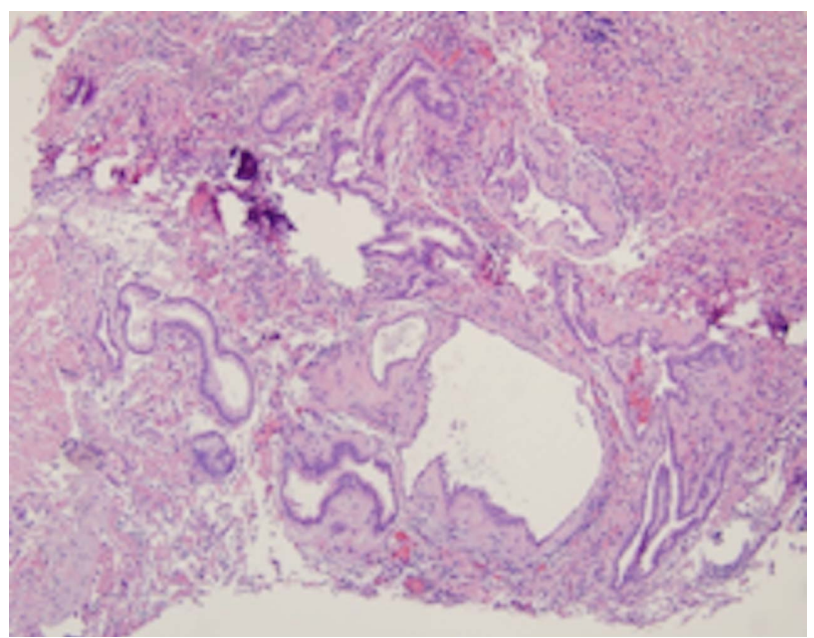

Figure 8. Histological analysis demonstrated presence of abundant mucin secretion and glandular epithelium.

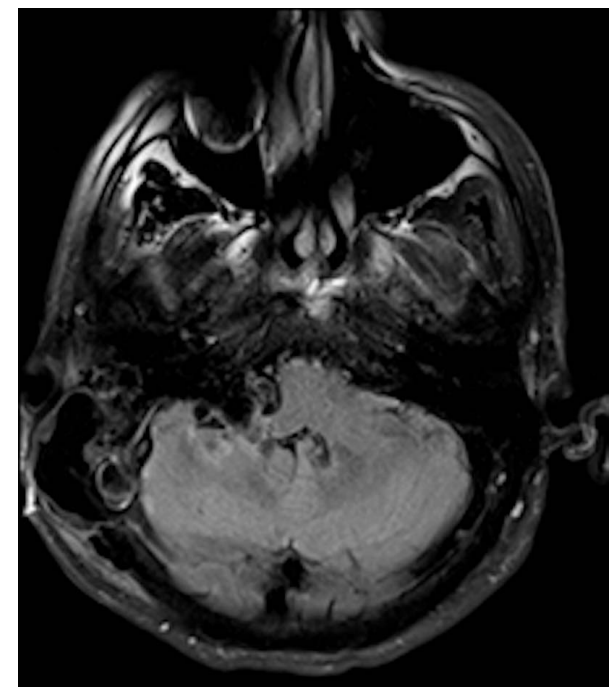

Figure 9. Post operative MRI showing complete resection and resolution of obstructive hydrocephalus. misplaced epithelium of the nasopharynx, respiratory tree, or intestinal tract and are characterized by their simple columnar, ciliated, or goblet cell epithelium [2]. They develop during the third or fourth week of embryonic development [2]. Only about 100 of these lesions have been described in the world literature [3]. These lesions are found in all age groups, although more commonly diagnosed in young adulthood [4]. Most of these lesions have been described to occur in the lower cervical spine and thoracic spine in an intradural-extramedullary fashion [5]. Intracranial enterogenous cysts are extremely rare with most of them located in the posterior fossa. The literature notes locations of cysts are as follows: within 4th ventricle [6], cerebellopontine angle [7], ventral brainstem [8], cerebellar vermis [9], within the medulla [10], and at the foramen magnum [11]. Supratentorial cysts are exceedingly rare with only 20 cases reported worldwide [12]. No previous reports of simultaneous upper cervical spine to ambient cistern giant multiloculated lesions have been described. Additionally, this lesion was very unusual in that it had at least 10 separate loculated compartments that were distinct and separate from one another.

These cysts are known to contain clear, gelatinous, mucoid or xanthochromic fluid [13]. In 1976, Wilkins and Odon classified these lesions into three groups based on their histological features. Type 1 cysts have a simple or pseudo stratified epithelium that can be cuboidal or columnar with or without cilia. Type 2 cysts have a more complex epithelium with respiratory or gastrointestinal tissues. Type 3 cysts are similar to type 2 cysts but also have glial or ependymal cells [14].

For giant intracranial cysts, the differential diagnosis should include glial tumors, epidermoid cysts, arachnoid cysts, dermoid cysts, infectious cysts, colloid cysts, metastatic tumors as well as enterogenous cysts. Treatment of choice for these lesions is total surgical resection of the cyst wall and drainage of the cyst contents. If the wall is not resected, these lesions may recur [15]. In cases where the wall cannot be completely excised due to difficulty separating arachnoid pial plane, partial resection is recommended with connection of the loculations to the subarachnoid space [16]. When partial resection is performed, symptomatic recurrence is documented at $31 \%$ at 2 months to 14 years [17].

\section{REFERENCES}

[1] M. Puusepp, "Variete Rare de Teratome, Sousdural de la Region Cervical (Intestionome): Quadriplegie, Extirpation Guerison Complete," Revue Neurologique, Vol. 2, 1934, pp. 879-886.

[2] S. Matsunaga, K. Fujitsu, S. Yagashita, T. Ichikawa, Y. Takemoto, Y. Takeda, et al., "Endodermal Cyst Ventral to the Lower Brainstem,” Neurologia Medico-Chirurgica, 
Vol. 46, No. 12, 2006, pp. 614-618. doi:10.2176/nmc.46.614

[3] R. R. Sharma, R. R. Ravi, N. T. Gurusinghe, C. Coutinho, A. K. Mahapatra, J. Sousa, et al., "Cranio-Spinal Enterogenous Cysts: Clinic-Radiolgoical Analysis in a Series of Ten Cases,” Journal of Clinical Neuroscience, Vol. 8, No. 2, 2001, pp. 133-139. doi:10.1054/jocn.2000.0792

[4] A. Perry, B. W. Scheitauer, B. W. Zaias and H. V. Minassian, "Aggressive Enterogenous Cyst with Extensive Craniospinal Spread: Case Report,” Neurosurgery, Vol. 44, No. 2, 1999, pp. 401-404. doi:10.1097/00006123-199902000-00098

[5] W. I. Silvernail Jr. and R. Brown, "Intramedullary Enterogenous Cyst,” Journal of Neurosurgery, Vol. 20, No. 2, 1972, pp. 235-238. doi:10.3171/jns.1972.36.2.0235

[6] F. Afshar and C. L. Scholtz, "Enterogenous Cyst of the Fourth Ventricle," Journal of Neurosurgery, Vol. 54, No. 6, 1981, pp. 836-838. doi:10.3171/jns.1981.54.6.0836

[7] S. Ito, S. Fujiwara, K. Mizoi, T. Namiki and T. Yosimoto, "Enterogenous Cyst at the Cerebellopontine Angle," Surgical Neurology, Vol. 37, No. 5, 1992, pp. 366-370. doi:10.1016/0090-3019(92)90005-8

[8] J. Lin, H. Feng, F. Li, Z. Chen and G. Wu, "Ventral Brainstem Enterogenous Cyst: An Unusual Location," Acta Neurochirurgica, Vol. 146, No. 4, 2004, pp. 419420. doi:10.1007/s00701-004-0227-2

[9] V. S. Mehta, C. Choudhary and R. Bhatia, "Neuroenteric Cyst of the Cerebellum," Potgraduate Medical Journal, Vol. 60, No. 702, 1984, pp. 287-289. doi:10.1136/pgmj.60.702.287

[10] A. Zalatnia, "Neurenteric Cyst of the Medulla Oblongata -A Curiosity," Neuropediatrics, Vol. 18, No. 1, 1987, pp. 40-41. doi:10.1055/s-2008-1052433
[11] H. Elmadbouh, S. F. Halpin, J. Neal, R. H. Hatgfield and M. D. Hourihan, "Posterior Fossa Epithelial Cyst: Case Report and Review of the Literature," AJNR, Vol. 20, No. 4, 1999, pp. 681-685.

[12] C. Christov, F. Chretien, P. Brugieres and M. Djindjian, "Giant Supratentorial Enterogenous Cysts: Report of a Case, Literature Review and Discussion of Pathogenesis," Neurosurgery, Vol. 54, No. 3, 2003, pp. 759-763. doi:10.1227/01.NEU.0000109538.07853.7F

[13] C. O. Harris, M. S. Dias, D. L. Brockmeyer, J. J. Townsend, B. K. Willis and R. I. Apfelbaum, "Neurenteric Cyst of the Posterior Fossa: Cognition, Management, and Embryogenesis,” Neurosurgery, Vol. 29, No. 6, 1991, pp. 893-897. doi:10.1227/00006123-199112000-00015

[14] R. H. Wilkins and G. L. Odon, "Spinal Intradural Cyst. Tumors of the Spine and Spinal Cord, Part II,” In: Handbook of Clinical Neurology, Vol. 20, North Holland, New York, 1976, pp. 55-102.

[15] G. P. Malcolm, L. Symon, B. Kendall and M. Pires, "Intracranial Neurenteric Cyst. Report of Two Cases,” Journal of Neurosurgery, Vol. 75, No. 1, 199, pp. 115-120. doi:10.3171/jns.1991.75.1.0115

[16] G. Beijani, D. C. Wright, D. Schessel and L. N. Sekhar, "Endodermal Cysts of the Posterior Fossa. Report of Three Cases and Review of the Literature," Journal of Neurosurgery, Vol. 89, No. 2, 1998, pp. 326-335. doi:10.3171/jns.1998.89.2.0326

[17] R. Perrini, S. A. Rutherford, A. T. King, D. Plessis and N. Lorenzo, "Enterogenous Cysts of the Cerebellopontine Angle: Short Review Illustrated by Two New Patients," Acta Neurochirurgica, Vol. 150, No. 2, 2008, pp. 177184. doi:10.1007/s00701-007-1483-8 